WORKING PAPER · NO. 2020-189

\title{
Pandemic-Era Uncertainty on Main Street and Wall Street
}

Brent Meyer, Emil Mihaylov, Steven J. Davis, Nicholas Parker, David Altig, Jose Maria Barrero, and Nicholas Bloom

DECEMBER 2020

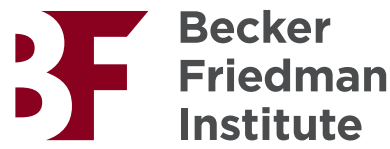




\title{
Pandemic-Era Uncertainty on Main Street and Wall Street
}

\author{
Brent Meyer, ${ }^{1}$ Emil Mihaylov, ${ }^{1}$ Steven J. Davis, ${ }^{2}$ Nicholas Parker, ${ }^{1}$ David Altig, ${ }^{1}$ Jose Maria \\ Barrero, ${ }^{3}$ and Nicholas Bloom, ${ }^{4}$
}

\section{December 2020}

\begin{abstract}
We draw on the monthly Survey of Business Uncertainty (SBU) to make three observations about pandemic-era uncertainty in the U.S. economy. First, equity market traders and executives of nonfinancial firms share similar assessments about uncertainty at one-year lookahead horizons. That is, the one-year VIX has moved similarly to our survey-based measure of (average) firm-level subjective uncertainty at one-year forecast horizons. Second, looking within the distribution of beliefs in the SBU reveals that firm-level expectations shifted towards upside risk in the latter part of 2020. In this sense, decision makers in nonfinancial businesses share some of the optimism that seems manifest in equity markets. Third, and despite the positive shift in tail risks, overall uncertainty continues to substantially dampen capital spending plans, pointing to a source of weak growth in potential GDP.
\end{abstract}

Keywords: Business Expectations, Uncertainty, Subjective Forecast Distributions, Surveys JEL Classification: L2, M2, O32, O33.

Disclaimer: Any opinions and conclusions expressed herein are those of the authors and do not necessarily represent the views of the Federal Reserve Bank of Atlanta. All results have been reviewed to ensure that no confidential information was disclosed.

Acknowledgements: We thank the Federal Reserve Bank of Atlanta, the Alfred P. Sloan Foundation and the University of Chicago Booth School of Business for financial support.

\footnotetext{
${ }^{1}$ Federal Reserve Bank of Atlanta, ${ }^{2}$ University of Chicago Booth School of Business and Hoover Institution, ${ }^{3}$ Instituto Tecnológico Autónomo de México Business School, and ${ }^{4}$ Stanford University,
} 
COVID-19 brought the most severe shock to hit the U.S. economy since at least the Great Depression. Concerns over the direct impact of the virus and the associated public policy response ushered in an era of enormous uncertainty. Businesses - our primary focus in this paper -- wrestled with a whole host of near-term (and potentially longer-term) pandemic-induced challenges and changes in the economy.

Still, in what some see as a paradox, 2020 was a banner year for equity markets. The early stages of the COVID-19 pandemic drove a spectacular rout in stock markets, but equity prices recovered sharply after March. By late December, the S\&P 500 index stood about 10 percent higher than its peak pre-pandemic value in February 2020. On the real side of the economy, in contrast, the outlook remains relatively downbeat, despite a strong rebound in 2020 Q3 and expectations of continued growth. If current growth projections are close to correct, U.S. GDP won't return to February 2020 levels until the fourth quarter of 2021. Even then, real GDP will remain well below its pre-pandemic trend. In contrast, equity values reached 2019 trend levels by the end of 2020 Q3.

In what follows, we use the national firm-level Survey of Business Uncertainty (SBU) to make three observations that relate to this "Main Street/Wall Street" dichotomy. First, equity market traders and executives of nonfinancial firms share similar assessments about uncertainty at one-year look-ahead horizons. That is, the one-year VIX has moved similarly to our surveybased measure of (average) firm-level subjective uncertainty at one-year forecast horizons. Second, looking within the distribution of beliefs in the SBU reveals that firm-level expectations shifted towards upside risk in the latter part of 2020. In this sense, decision makers in nonfinancial businesses share some of the optimism that seems manifest in equity markets. Third, and despite the positive shift in tail risks, overall uncertainty continues to substantially dampen capital spending plans, pointing to a source of weak growth in potential GDP.

\section{The Survey of Business Uncertainty}

Our measure of business uncertainty is obtained from responses to the Survey of Business Uncertainty, a monthly panel survey that elicits business executives' subjective beliefs over their own firm-level outcomes (see Altig et al. 2020 for an in-depth discussion). Panelists are recruited by phone from available population databases of nonfarm businesses. The online survey instrument is delivered each month and has been continuously fielded since 2014. As of December 2020, we have data on roughly 1800 firms drawn from all 50 states, every major nonfarm industry, and for a wide range of firm sizes. Response rates have been relatively stable at about 20 percent of the full sample, yielding about 460 responses per month. For "active" respondents - that is, panelists who have responded at least once in the prior 6 months - the response rate is approximately 50 percent.

Core survey questions elicit five-point probability distributions (mass points and associated probabilities) over each firm's own future sales revenue and employment growth rates at a one-year look-ahead horizon. Letting respondents freely choose support points on the distribution and associated probabilities avoids anchoring bias and allows for great flexibility in 
describing beliefs. In particular, expected growth rates can be high or low and firm-level belief distributions can be tight or dispersed, positively or negatively skewed, and thin or fat-tailed. Using these subjective probability distributions allows us to measure firm-level expectations and subjective uncertainty about future growth rates of sales and employment. Firm-level growth rate expectations are highly predictive of realized growth rates, as we document in Altig et al (2020). Firm-level subjective uncertainty is highly predictive of forecast error magnitudes and the size of future forecast revisions, as we also show in our earlier work.

SBU data can be used to construct time series of subjective expectations over sales revenue and employment growth from weighted averages of the firm-level data. These aggregated results are generally consistent with other forecasts of economic growth. For example, the consensus Blue Chip GDP Q4/Q4 growth forecast for 2020 nominal GDP was approximately 3.8 percent in December 2019. The SBU aggregate expectation for 12-month ahead sales growth that month was 3.7 percent. $^{1}$

As noted, the SBU elicits each firm's distribution of beliefs about its own future outcomes. This lets us to construct aggregate measures of business uncertainty by aggregating over subjective firm-level uncertainty measures. While the SBU is a young survey, our approach to eliciting subjective probability distributions from business decision makers has been adopted in several other surveys with large-scale institutional backing. Since 2016, the Bank of England, in partnership with the University of Nottingham, has fielded a monthly survey of U.K. firms (see Bloom et al., 2017) that adopts the SBU question design. The U.S. Census Bureau fielded questions with the SBU design in the Management and Organizational Practices Survey (Buffington et al., 2017 and Bloom et al., 2020). The World Bank used the SBU approach to eliciting subjective probability distributions in a coordinated global survey effort to better understand the impact of the COVID-19 pandemic (Apedo-Amah et al, 2020).

\section{Uncertainty during the COVID-19 Pandemic on Main Street and Wall Street}

Unsurprisingly, businesses uncertainty surged after the onset of the COVID-19 pandemic in March 2020. As documented in Figure 1, both the SBU uncertainty index and the similarly constructed U.K. DMP index rose well in excess of any of their previous peaks. Firms' uncertainty regarding sales revenue growth more than doubled at the outset of the pandemic. And, while the history for these series is short, the pandemic-onse episode dwarfs any pickup in uncertainty around the Tax Cuts and Jobs Act in late 2017 or during the 2018-19 period marked by increasing tariffs and global trade tensions. ${ }^{2}$

\footnotetext{
${ }^{1}$ Nominal GDP from the Blue Chip panel is simply the sum of real GDP and GDP price index forecasts. The SBU data is a 2-month moving average of the aggregate index. The SBU panel is divided into halves that answer either the employment growth questions or the sales growth questions in each survey round. Thus, in any given month half the panelists respond to the sales growth question. This design reduces respondent burden and promotes panel retention, though at the cost of inducing some variability in the monthly responses.

2 The DMP was launched subsequent to the June 2016 Brexit referendum. Though the SBU has been conducted in some form since 2014, a methodologically-consistent series also post-dates Brexit.
} 
Figure 1: Survey of Business Uncertainty (United States) and Decision Maker Panel (United Kingdom) Uncertainty Indexes

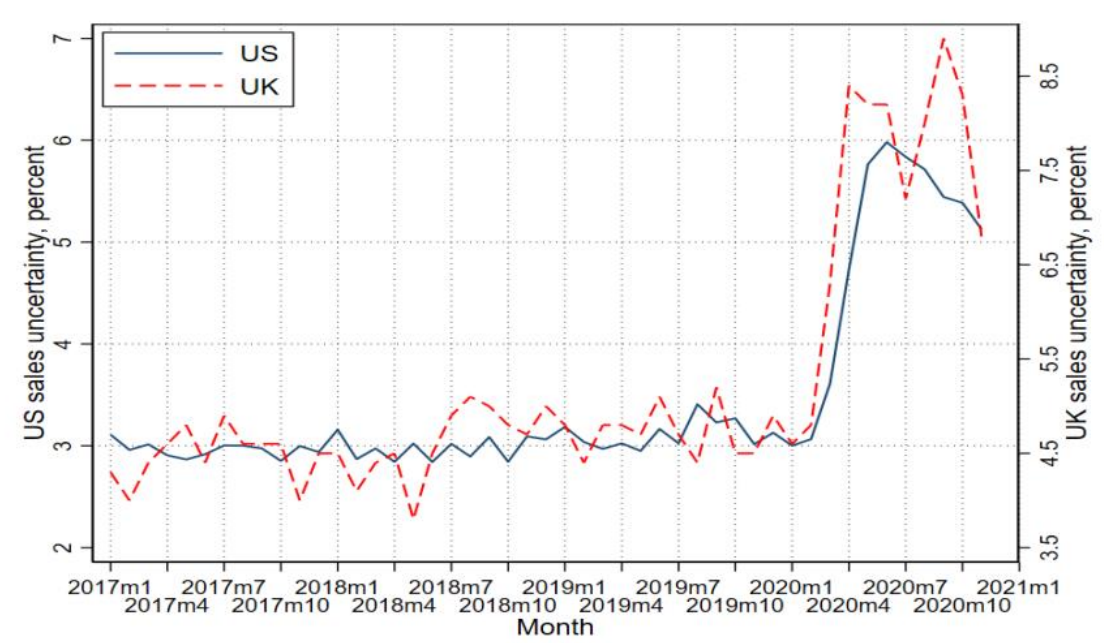

Sources: Atlanta Fed/Chicago Booth/Stanford Survey of Business Uncertainty; Bank of England/University of Nottingham Decision Maker Panel

In figure 2 we compare the rise in firms' forward-looking sales growth uncertainty to three alternative measures of uncertainty. The first two, the 3-month and 1-year VIX, are familiar metrics of financial market uncertainty. The third, the Economic Policy Uncertainty (EPU) Index of Baker, Bloom, and Davis (2015), is an index based on the frequency of newspaper articles that contain one or more terms in each of three categories pertaining to the economy, policy matters, and uncertainty. While there are many measures of uncertainty - see, for example, the discussion in Barrero and Bloom (2020) - we choose these measures as a basis of comparison, because they are well-known forward-looking uncertainty measures and are available in real time. To facilitate comparability, we normalize each series by its own average over the period from January 2019 through February 2020.

Two features stand out in figure 2. First, though all measures spiked in March 2020, the changes in the 3-month VIX and the EPU were extreme relative to the survey-based measures and the 1-year VIX. Second, all measures save the EPU have settled into levels that are roughly 50 to 75 percent higher than their pre-pandemic averages. Third, while still elevated, the 3month VIX and EPU signal a very substantial decline in overall uncertainty since the early stages of the pandemic. The other three indexes, in contrast, suggest a much more modest abatement of uncertainty relative to the spring. 
Figure 2: Wall Street vs. Main Street Uncertainty

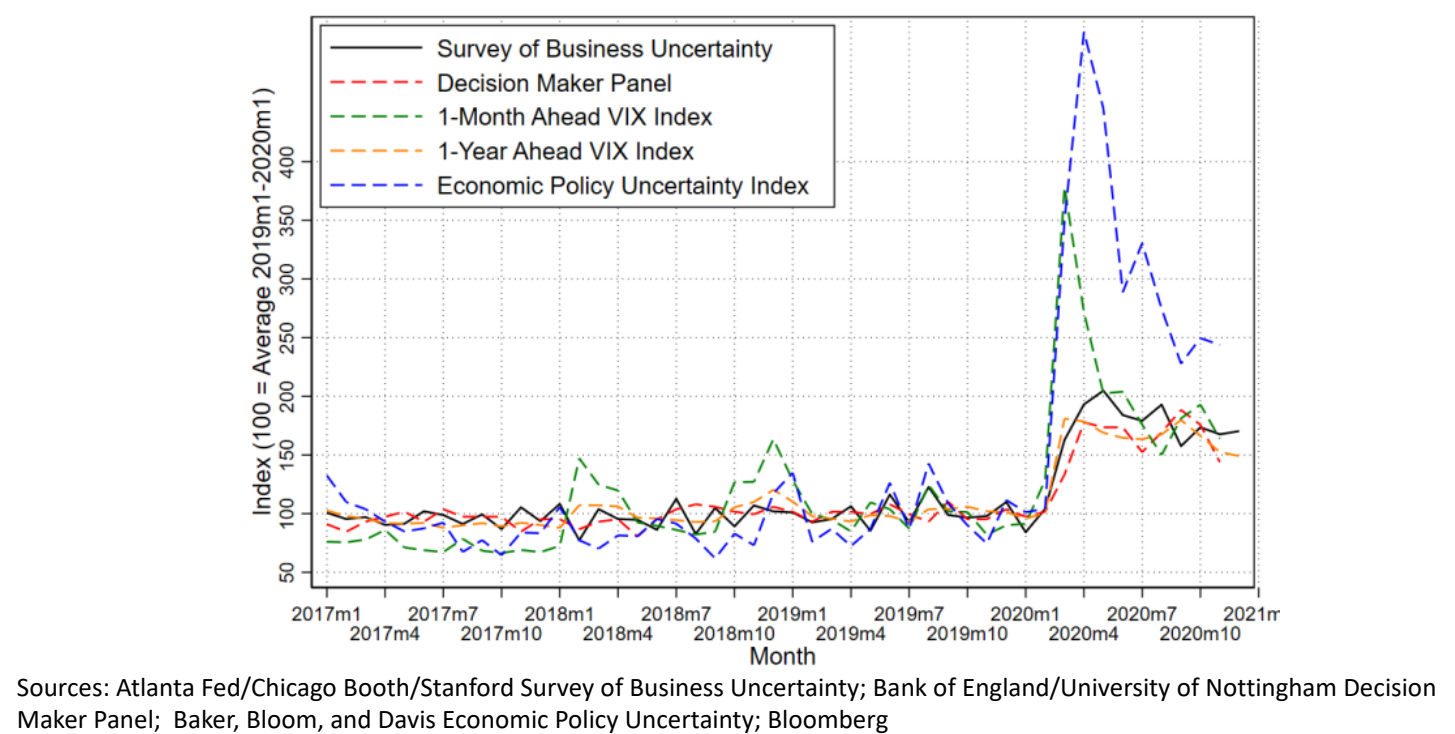

The strongly similar patterns for the 1-year VIX, the SBU measure, and DMP measure at least partly reflects the alignment of the horizon over which uncertainty is measured: Sales growth rate forecasts in both the SBU and DMP are defined at 12-month horizons. The message from this is not that one set of measurements is superior to the others, but instead is the rather obvious point that the time period over which uncertainty is defined matters. With respect to questions that fundamentally involve the expectations of nonfinancial decision makers over something like an annual horizon, the 1-year VIX seems a clearly better proxy than alternatives that do not so closely align with that horizon.

\section{A Deeper Dive into the Distribution of Beliefs}

One message from figure 2 is that aggregate uncertainty remains substantially elevated relative to the pre-pandemic norm. What is not apparent from the aggregate uncertainty measure is that, at least in the United States, the distribution of beliefs that underlie the overall uncertainty measure has shifted after the initial shock. Figure 3 shows the evolution of average firm-level beliefs derived from the SBU. It is an updated version of a chart first shown in Barrero and Bloom (2020), and the details of its construction can be found therein.

We highlight three aspects of Figure 3. First, the median of future sales growth fell markedly at the outset of the pandemic and has since recovered to near its typical level. At first blush, that may seem an optimistic return toward "normality," but it's important to recognize that these projections are growth rates conditioned on current levels of activity. Because sales fell dramatically as a result of the pandemic shock, the median (and mean) projections are quite 
pessimistic, as they imply that that firms do not anticipate regaining their pre-COVID sales levels through the end of 2021.

\section{Figure 3: The Evolving Distribution of Firm-level Beleifs}

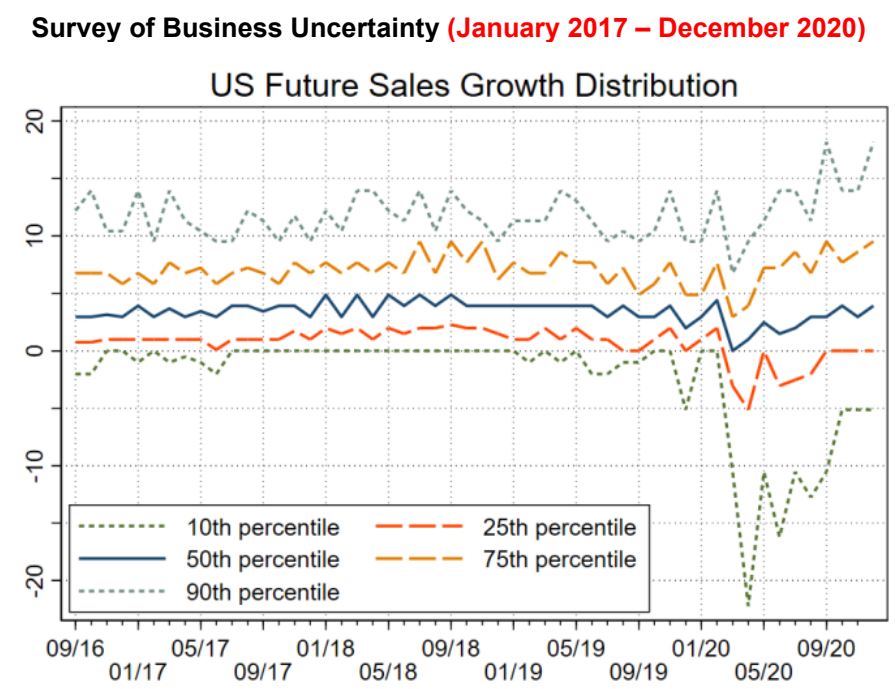

Source: Atlanta Fed/Chicago Booth/Stanford Survey of Business Uncertainty

Second, the figure reveals the not-so-shocking result that the lower tail of the subjective sales growth rate distribution became much more negative. Taking the 10th percentile outcome as a plausible estimate of a typical firm's worst-case scenario, zero growth is a reasonable lower bound on the average firm-level expected outcomes before the pandemic. That worst-case scenario fell to below -20 percent in April 2020. While it has since moved in the direction of less pessimism, it remains well below zero through December 2020.

Third, Figure 3 reveals that the distribution of outcomes has become increasingly concentrated in the upper tail of the growth rate distribution. Over the past quarter, the deviation of beliefs relative to the pre-pandemic norm has shifted from the lower tail to the upper one. Thus, the beliefs that underlie our overall uncertainty measure have become more optimistic.

\section{Whither Capital Expenditures?}

One attractive feature of the SBU is its capacity to enhance our understanding of uncertainty and its effects through special surveyquestions. These questions let us probe the perceived effects of specific economic and policy developments on actual and anticipated firmlevel outcomes. Aggregating over the firm-level responses to these special questions can yield estimates for the causal effects of policy developments and various shocks to the macro environmene. See, for example, Altig et al. (2018, 2019).

Starting in September 2020 and continuing through December 2020, we asked panelists to rank order the top 3 sources of uncertainty impacting their decision-making processes. As shown in figure 4, COVID-19 emerged as the top concern by far. It was not the only one, 
however. In fact, COVID-19 was not reported as the top source of uncertainty for a significant share of businesses. The November 2020 elections emerged as the second ranked source of uncertainty for firms during the last 4 months of 2020. The share of firms viewing the elections as their top source of uncertainty dipped from 18 percent in October to 12 percent in the November survey (fielded from November 9-20). tt rebounded to 16 percent in December, perhaps because runoff-election outcomes in Georgia and which party would control the U.S. Senate remained unknown.

Figure 4: Sources of Uncertainty Currently Influencing Business Decision Making of Firms

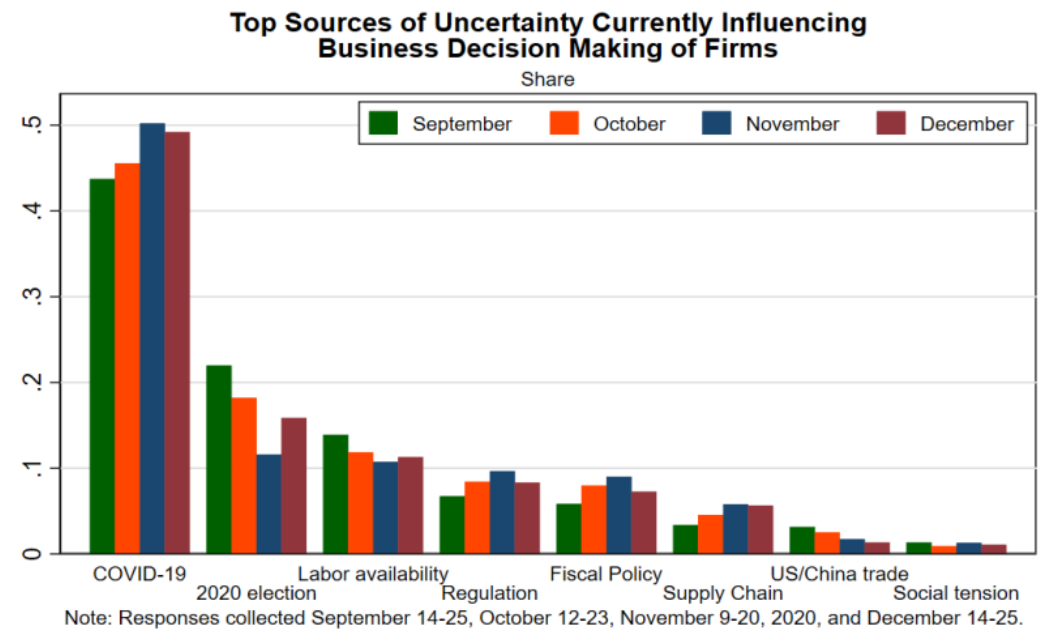

Source: Atlanta Fed/Chicago Booth/Stanford Survey of Business Uncertainty

In the October 2020 SBU, we queried participants about the impact of uncertainty on their planned capital expenditures. Specifically, we asked "Are the uncertainties you just identified causing your firm to alter its budget for capital expenditures for calendar years 2021 and 2022?" The response options were yes (increasing), yes (decreasing), and no. For those that said yes: Then we asked this question: "By what percentage has the net budgeted dollar amount of your capital expenditures for calendar years 2021 and 2022 [increased/decreased] due to the uncertainties you identified above?" Table 2 reports (sales-weighted) mean aggregate responses.

Table 2: Survey-Based Estimates of How Uncertainty in 2020 Affected Actual and Planned Capital Expenditures in 2021 and 2022

\begin{tabular}{|l|c|}
\hline Industry & $\begin{array}{l}\text { Sales-weighted mean } \\
\text { Uncertainty Effect (percent) }\end{array}$ \\
\hline Overall & -15.7 \\
\hline Construction, Real Estate, and Mining & -23.6 \\
\hline Manufacturing & -14.9 \\
\hline Retail and Wholesale Trade & -12.1 \\
\hline Business Services & -15.8 \\
\hline Other Services & -16.9 \\
\hline
\end{tabular}


As table 2 reports, the survey-based measure of uncertainty's impact on capital expenditures in 2020 and 2021 is large and negative across broad sectors. This, despite the shift in the belief distribution from downside tail risks in the early stages of the pandemic to upside tail risks in the latter part of 2020. $t$

\section{Concluding remarks}

Our survey results support the commonsense conclusion that COVID-related uncertainty remains a dominant feature of the decision-making environment for businesses. In fact, contrary to the implication one might draw from some measures of uncertainty, such as the 3-month VIX, uncertainty has declined only modestly from peak levels in the spring.

What is less appreciated is how the nature of the uncertainty perceived by businesses has shifted since the early phases of the pandemic: Downside tail risk have diminished considerably, and upside tail risks have grown. Nonetheless, firms continue to report that high uncertainty exerts a substantial drag on their actual and anticipated capital expenditures.

The trajectory of business investment spending is of great importance for the future path of productivity and GDP. We believe that firm-level surveys like the SBU can, and will, play a key role in monitoring these important developments as we proceed through the pandemic and assess the policy post-COVID landscape.

\section{References}

Altig, David, Jose Marie Barrero, Nicholas Bloom, Steven J. Davis, Brent Meyer, and Nicholas Parker. 2020. "Surveying business uncertainty" Journal of Econometrics. https://doi.org/10.1016/i.jeconom.2020.03.021

Altig, David, Jose Maria Barrero, Nicholas Bloom, Steven J. Davis, Brent Meyer, Emil Mihalov, and Nicholas Parker. 2019. "New Evidence Points to Mounting Trade Policy Effects on U.S. Business Activity" Macroblog Federal Reserve Bank of Atlanta. https://www.frbatlanta.org/blogs/macroblog/2019/11/01/new-evidence-points-to-mounting-tradepolicy-effects-on-us-business-activity.aspx

Altig, David, Nicholas Bloom, Steven J. Davis, Brent Meyer, and Nicholas Parker. 2018. "What Are Businesses Saying About Tax Reform Now?" Macroblog Federal Reserve Bank of Atlanta. https://www.frbatlanta.org/blogs/macroblog/2018/03/23/what-are-businesses-saying-about-taxreform-now.aspx

Apedo-Amah, Besart Avdiu, Xavier Cirera, Marcio Cruz, Elwyn Davies, Arti Grover, Leonardo Iacovone, Umut Kilinic, Denis Medvedev, Franklin Okechukwu Maduko, Stavros Poupakis, Jesica Torres, and Trang Thu Tran. 2020. "Unmasking the Impact of Covid-19 on Businesses. Firm Evidence from Across the World.” Policy Research Working Paper 9434, World Bank. http://documents1.worldbank.org/curated/en/399751602248069405/pdf/Unmasking-the-Impactof-COVID-19-on-Businesses-Firm-Level-Evidence-from-Across-the-World.pdf 
Baker, Scott, Nicholas Bloom, and Steven J. Davis. 2016. "Measuring Economic Policy Uncertainty" Quarterly Journal of Economics, 131, no. 4 (November), 1593-1636.

Barerro, Jose Maria and Nicholas Bloom. 2020. "Economic Uncertainty and the Recovery" 2020 Economic Symposium, Federal Reserve Bank of Kansas City. https://www.kansascityfed.org/ /media/files/publicat/sympos/2020/jh_final.pdf?la=en

Bloom, Nicholas, Philip Bunn, Paul Mizen, Pawel Smietanka, Greg Thwaites, and Gary Young. 2017. "Tracking the views of British businesses: evidence from the Decision Maker Panel" Quarterly Bulletin, Bank of England. https://www.bankofengland.co.uk/quarterlybulletin/2017/q2/tracking-the-views-of-british-businesses-evidence-from-the-dmp

Bloom, Nicholas, Steven J. Davis, Lucia Foster, Brian Lucking, Scott Ohlmacher and Itay Saporta-Eckstein, 2020. "Business-Level Expectations and Uncertainty," NBER Working Paper 28259.

Buffington, Catherine, Lucia Foster, Ron Jarmin, and Scott Ohlmacher. 2017. "The Management and Organizational Practices Survey (MOPS): An Overview" U.S. Census Bureau. https://www.census.gov/content/dam/Census/library/workingpapers/2017/econ/buffington-01.pdf 